\title{
Patients' Understanding of the Relationship Between Their Diabetes and Periodontal Disease
}

\author{
Oluwamurewa Oguntimein, PhD, MHS, CPH, CHES, James Butler III, DrPH, Med, \\ Sharon Desmond, PhD, Kerry M. Green, PhD, Xin He, PhD, and \\ Alice M. Horowitz, $\mathrm{PhD}$
}

Introduction: There is a paucity of research on awareness, education, and interventions that address increased risk of developing periodontal disease, the sixth complication of diabetes. Examining the knowledge of patients with diabetes and understanding of the bidirectional relationship between periodontal disease and diabetes could inform future diabetes self-management care. We assessed the knowledge and understanding of the bidirectional relationship between diabetes and periodontal disease; examined gender, education, and income differences in this knowledge and understanding, as well as other differences in dental hygiene practices.

Methods: A Web-based survey was conducted using a convenience sample of patients with diabetes.

Results: A total of 927 patients with diabetes participated in the study. Gender and education were significantly associated with knowledge and understanding of the bidirectional relationship between diabetes and periodontal disease in patients with diabetes. After controlling for diabetes duration, dental insurance status, and other covariates, males had less knowledge and understanding of the bidirectional relationship between diabetes and periodontal disease compared with females $(P<.0001)$. Those with higher education $(P<.002)$ and those who received health care provider recommendations to obtain regular dental visits $(P<.00001)$ had greater understanding of the association between diabetes and periodontal disease.

Conclusions: This study highlights the need for 1) educating male and low-education patients with diabetes in particular about their increased risk of periodontal disease and the need for regular dental visits, and 2) health care providers and dental health providers to work together to address the needs of their diabetic patients. ( $\mathrm{J}$ Am Board Fam Med 2020;33:1004-1010.)

Keywords: Diabetes Mellitus, Health Behavior, Health Personnel, Oral Hygiene, Patient Navigation, Periodontal Diseases, Self-Management, Surveys and Questionnaires

\section{Introduction}

Background

In 2017, 83,564 Americans died from diabetes, making it 1 of the 10 leading causes of death. ${ }^{1}$ Diabetes

This article was externally peer reviewed.

Submitted 19 December 2019; revised 1 May 2020; accepted 18 May 2020

From the Department of Behavioral and Community Health, School of Public Health, University of Maryland, College Park (OO, JB, KMG, AMH); Department of Epidemiology and Biostatistics, School of Public Health, University of Maryland, College Park (XH).

\section{Funding: None.}

Conflict of interest: None.

Corresponding author: Oluwamurewa Oguntimein, $\mathrm{PhD}$, MHS, CPH, CHES, Department of Behavioral and Community Health, SPH Building \#255, Suite 1234, 4200 Valley Drive, University of Maryland, College Park, MD 207426011 (E-mail: murewa.oguntimein@gmail.com). management reached $\$ 327$ billion (\$237 billion direct medical costs and $\$ 90$ billion indirect costs). ${ }^{2}$ These exorbitant costs are related to diabetes comorbidities: hypertension, heart disease, stroke, kidney disease, amputation, blindness, and periodontal disease. ${ }^{3}$ Currently, there are 30 million Americans living with diabetes. ${ }^{4}$

Research has assessed the knowledge and understanding of patients with diabetes of their increased risk for chronic diseases and complications. ${ }^{5-8}$ However, few studies have examined awareness, education, and interventions that address increased risk of developing periodontal disease, the sixth complication of diabetes. ${ }^{9,10}$ Diabetes and periodontal disease have a bidirectional relationship. ${ }^{11-17}$

Based on this bidirectional relationship, periodontal disease is more prevalent among patients 
with diabetes. National Health Nutrition Examination Survey data suggest that prevalence of severe periodontitis in patients with diabetes was significantly higher than that of people without diabetes. ${ }^{18}$ Similarly, periodontitis is a predictor of diabetes death. One study of patients with diabetes found age- and sex-adjusted death rates were 3.7 for those with no or mild periodontitis, 19.6 for moderate periodontitis, and 28.4 for severe periodontitis. Periodontitis predicts death from diabetic nephropathy $(P<.01)$ and ischemic heart disease $(P=.04) .{ }^{19}$ Poorer periodontal health leads to poorer glycemic control. ${ }^{20-24}$ Thus, by treating periodontal disease, a positive effect on glycemic control is observed in patients with type 1 and type 2 diabetes. $^{25-30}$ One meta-analysis (9 studies; 485 patients with diabetes) reported a significant reduction in $\mathrm{HbA}_{1 \mathrm{c}}$ of $0.46 \%$ (95\% CI, 0.11-0.82; $P=.01$ ) following periodontal treatment. ${ }^{31}$ Despite evidence supporting a diabetes and periodontal disease bidirectional relationship, few studies have assessed the knowledge and understanding of the bidirectional relationship between these 2 diseases in patients with diabetes. This information is important for health care providers. It can shape their diabetes education messages for patients. The study reported here examined knowledge and understanding of the bidirectional relationship between diabetes and periodontal disease (hereafter, bidirectional relationship) and factors associated with this knowledge in patients with diabetes.

\section{Methods}

\section{Study Design}

In August 2019, we conducted a Web-based survey to understand the knowledge and understanding of the bidirectional relationship in adult patients with diabetes. We assessed gender, education and income, differences, and gender, education, and income differences regarding health care providers recommending regular dental visits. All data were self reported.

\section{Sample and Procedure}

Participants were $\geq 18$ years old, living with type 1 or type 2 diabetes, read, spoke, and understood English. They were recruited from a marketing research company's online patient panel because of its efficiency with reaching a broad population. ${ }^{32,33}$ Each participant provided consent, completed the survey, and received a \$6 gift card for participating. The University of Maryland-
College Park Institutional Review Board approved this research.

\section{Measures}

The survey was developed using validated questions and scales from previous surveys. We included diabetes and periodontal disease questionnaire of Smith and colleagues ${ }^{34}$ to measure knowledge and understanding of the bidirectional relationship. ${ }^{34}$ Demographic questions (gender, age, race/ethnicity, education, employment, marital status, income, smoking habits) were from the Behavioral Risk factor Surveillance System (BRFSS). ${ }^{35}$ Participants' diabetes type, family history, treatment regimen, diabetes education session attendance, and health care provider recommendations for regular dental visits were queried.

For analysis, education was dichotomized into 12 th grade and below versus above 12 th grade, and annual income into low $(\leq \$ 50,000)$, middle $(\$ 51,000$ $\$ 100,000)$, or high $(\geq \$ 101,000)$ to better reveal the association between health care providers dental visit recommendations and outcomes of interest. Brushing and flossing questions were obtained from the existing literature. ${ }^{36-38}$ One BRFSS question captured participants dental visit practices. ${ }^{35}$

\section{Analytic Procedures}

Descriptive statistics were used to describe the demographic information for categorical variables proportions, survey responses on the 5-point Likert scale (percentages) were reported, and continuous variables were reported as means with standard deviations. Multiple linear regression was used to evaluate the association of gender, education, and income with knowledge and understanding of the bidirectional relationship. Chi-squares determined gender, education, and income differences in health care providers' dental visit recommendations. Statistical analyses were performed using SPSS version 25 (IBM, Armonk, NY).

\section{Results}

Of the 1587 participants who consented to participate, 927 (58\%) completed the survey, 223 (14.0\%) were excluded because the quota for female participants was met, and 437 (27.5\%) did not complete the survey. Participants were majority female $(n=527$; $56.9 \%$ ) with a mean age of 54.63 ( \pm 14.56$)$ years. More than half of the participants were white $(n=581$; 
$62.7 \%), 341$ (36.8\%) had a high-school diploma or GED, 297 (32.0\%) were retired, 441 (47.6\%) were married, and 468 (50.5\%) had attended a diabetes education session in the past. Knowledge and understanding of the bidirectional relationship was $5.79 \pm 2.366$ (range, 0 to 10). Overall, 52.5\% reported brushing their teeth more than once a day, $42.4 \%$ visited the dentist twice a year, and $38.6 \%$ flossed once or more per day (Table 1).

\section{Health Care Provider Recommending Regular Dentist Visits}

Forty-one percent indicated their health care provider recommended regular dental visits. Education and income differences were associated with health care provider recommending regular dental visits; $38.6 \%$ with a high school diploma or less indicated that their health care provider recommended regular dentist visits compared with $45.5 \%$ of participants with more than a high school diploma $(P=.037)$. Only $37.1 \%$ of low-income participants indicated that their health care provider recommended regular dentist visits, whereas $48.3 \%$ of middle-income and $53.8 \%$ high-income participants $(P=.0001)$ received dental visit recommendations.

\section{Health Care Provider Recommending Dental Visits' Associations: Gender, Education, Income}

The association of gender, education, and income with knowledge and understanding of the bidirectional relationship was examined using linear regression (Table 2). We controlled for diabetes type, disease duration, education session, treatment, family history, smoking status, marital status, dental insurance, and health care provider recommending dental visits.

Gender was significantly associated with diabetes and periodontal diseases' bidirectional relationship ( $\mathrm{b}=-0.038 ; P<.0001 ; 95 \% \mathrm{CI},-0.056$ to -0.019 ) (Table 2). Males had less knowledge and understanding of the bidirectional relationship. Education was also associated with knowledge and understanding of the bidirectional relationship after controlling for covariates $(b=0.030, P<.002$; 95\% CI, 0.0110.049) (Table 2). Participants with more than a high school diploma had more knowledge and understanding of the bidirectional relationship than those with less education. In addition, health care provider recommending regular dental visits was positively associated with knowledge and understanding $(b=0.036$; $P<.0001$; 95\% CI, 0.018-0.054) of the bidirectional
Table 1. Characteristics of Patients with Diabetes $(\mathrm{n}=927)$

\begin{tabular}{|c|c|}
\hline Characteristics & $\begin{array}{c}\text { Total Response, } \\
\text { N (\%) }\end{array}$ \\
\hline \multicolumn{2}{|l|}{ Gender } \\
\hline Female & $527(56.9)$ \\
\hline Male & $400(43.1)$ \\
\hline Age, years, mean (SD) & $54.63(14.6)$ \\
\hline \multicolumn{2}{|l|}{ Ethnicity and race } \\
\hline Non-Hispanic White & $581(62.7)$ \\
\hline Black/African American & $147(15.9)$ \\
\hline Hispanic, Latino, Spanish origin & $142(15.3)$ \\
\hline Pacific Islander & $25(2.7)$ \\
\hline Asian & $17(1.8)$ \\
\hline Other & $11(1.2)$ \\
\hline \multicolumn{2}{|l|}{ Education } \\
\hline $\begin{array}{l}\text { Never attended school or only } \\
\text { attended kindergarten }\end{array}$ & $2(0.2)$ \\
\hline Grades 1 to 8 & $27(2.9)$ \\
\hline Grades 9 to 11 & $146(15.7)$ \\
\hline Grade 12 or GED & $341(36.8)$ \\
\hline College years 1 to 3 & $207(22.3)$ \\
\hline College 4 years or more & $130(14.0)$ \\
\hline Masters & $53(5.7)$ \\
\hline Doctoral/professional degree & $21(2.3)$ \\
\hline \multicolumn{2}{|l|}{ Employment } \\
\hline Employed & $266(28.7)$ \\
\hline Self employed & $46(5.0)$ \\
\hline Out of work for 1 year or more & $25(2.7)$ \\
\hline Out of work for less than 1 year & $7(0.8)$ \\
\hline Homemaker & $73(7.9)$ \\
\hline Student & $15(1.6)$ \\
\hline Retired & $297(32.0)$ \\
\hline Unable to work & $195(21.0)$ \\
\hline Prefer not to answer & $3(0.3)$ \\
\hline \multicolumn{2}{|l|}{ Income } \\
\hline$\$ 25000$ or less & $312(33.7)$ \\
\hline$\$ 26000$ to $\$ 35,000$ & $105(11.3)$ \\
\hline$\$ 36000$ to $\$ 50,000$ & $147(15.9)$ \\
\hline$\$ 51000$ to $\$ 75,000$ & $39(15.0)$ \\
\hline$\$ 76000$ to $\$ 100,000$ & $76(8.2)$ \\
\hline$\$ 101000$ to $\$ 150,000$ & $81(8.7)$ \\
\hline$\$ 151000$ to $\$ 200,000$ & $21(2.3)$ \\
\hline$\$ 201000$ or more & $15(1.6)$ \\
\hline Don't know/not sure & $7(0.8)$ \\
\hline Prefer not to answer & $24(2.6)$ \\
\hline \multicolumn{2}{|l|}{ Marital status } \\
\hline Married & $441(47.6)$ \\
\hline Never married & $192(20.7)$ \\
\hline Divorced & $129(13.9)$ \\
\hline Widowed & $73(7.9)$ \\
\hline A member of an unmarried couple & $56(6.0)$ \\
\hline
\end{tabular}


Table 1. Continued

Table 1. Continued

\begin{tabular}{|c|c|}
\hline Characteristics & $\begin{array}{l}\text { Total Response, } \\
\text { N (\%) }\end{array}$ \\
\hline Separated & $31(3.3)$ \\
\hline Prefer not to answer & $5(0.5)$ \\
\hline \multicolumn{2}{|l|}{ Self efficacy } \\
\hline Mean \pm SD (range) & $23.04 \pm 4.48(4$ to 29$)$ \\
\hline \multicolumn{2}{|l|}{ Diabetes type } \\
\hline Type 1 & $95(10.2)$ \\
\hline Type 2 & $832(89.8)$ \\
\hline \multicolumn{2}{|l|}{ Diabetes treatment } \\
\hline Yes & $917(98.9)$ \\
\hline No & $10(1.1)$ \\
\hline \multicolumn{2}{|l|}{ Family history of diabetes } \\
\hline Yes & $712(76.8)$ \\
\hline No & $207(22.3)$ \\
\hline Don't know/not sure & $8(0.9)$ \\
\hline \multicolumn{2}{|c|}{ Diabetes education session in the past } \\
\hline Yes & $468(50.5)$ \\
\hline No & $455(49.1)$ \\
\hline Prefer not to answer & $4(0.4)$ \\
\hline \multicolumn{2}{|l|}{$\begin{array}{l}\text { Healthcare provider recommended } \\
\text { regulardentist visit }\end{array}$} \\
\hline Yes & $380(41.0)$ \\
\hline No & $532(57.4)$ \\
\hline Don't know/not sure & $8(0.9)$ \\
\hline Prefer not to answer & $7(0.8)$ \\
\hline \multicolumn{2}{|l|}{ Dental insurance } \\
\hline Yes & $577(62.2)$ \\
\hline No & $347(37.4)$ \\
\hline Prefer not to answer & $3(0.3)$ \\
\hline \multicolumn{2}{|c|}{$\begin{array}{l}\text { Diabetes and periodontal disease } \\
\text { knowledge and understanding scale }\end{array}$} \\
\hline Mean \pm SD (range) & $5.79 \pm 2.366(0$ to 10$)$ \\
\hline \multicolumn{2}{|l|}{ Dentist visit frequency } \\
\hline Once a year & $200(21.6)$ \\
\hline Twice a year & $393(42.4)$ \\
\hline Once every 2 years & $52(5.6)$ \\
\hline Only for emergency treatment & $69(7.4)$ \\
\hline Years ago & $53(5.7)$ \\
\hline More than 5 years ago & $114(12.3)$ \\
\hline Never been & $18(1.9)$ \\
\hline Prefer not to answer & $28(3.0)$ \\
\hline \multicolumn{2}{|l|}{ Brushing frequency } \\
\hline Once a day & $331(35.7)$ \\
\hline More than once a day & $487(52.5)$ \\
\hline Once/twice a week & $59(6.4)$ \\
\hline \multicolumn{2}{|l|}{ Flossing frequency } \\
\hline Never & $161(17.4)$ \\
\hline Hardly ever & $204(22.0)$ \\
\hline Once/twice a week & $176(19.0)$ \\
\hline
\end{tabular}

Continued

\begin{tabular}{lc}
\hline Characteristics & $\begin{array}{c}\text { Total Response, } \\
\text { N (\%) }\end{array}$ \\
\hline Once a day & $221(23.8)$ \\
More than once a day & $137(14.8)$ \\
Prefer not to answer & $28(3.0)$ \\
\hline
\end{tabular}

SD, standard deviation; GED, General Equivalency Diploma.

relationship. However, income was not significantly associated with knowledge and understanding of the bidirectional relationship, after controlling for covariates $(P=.068)$.

\section{Discussion}

To our knowledge, this is the first study that examined patients with diabetes' characteristics (gender, education, income), health care providers' recommending regular dental visits and knowledge and understanding the diabetes and periodontal disease bidirectional relationship. We identified factors that predicted less understanding, which is important for targeted prevention/education efforts. Gender, education, health care providers' recommending regular dental visits and diabetes treatment were all associated with knowledge and understanding of the bidirectional relationship; interestingly, income was not associated with knowledge and understanding. It is imperative for health care providers to educate their prediabetics and patients with diabetes, about their increased risk of developing periodontitis. Educational sessions should include preventing periodontitis by brushing twice a day, flossing at least once a day, and obtaining routine dental care. ${ }^{39}$ Only $41.0 \%$ of participants indicated their health care provider recommended regular dentist visits because of their diabetes. Our findings underscore the critical role of health care providers regarding oral health education in diabetes self management. Research has shown that receiving dental hygiene information from health care providers after diabetes diagnosis was significantly associated with dental hygiene knowledge and practices. $^{40}$ Providers ought to recommend diabetes education sessions to newly diagnosed patients with diabetes and refresher sessions for current patients with diabetes. Because periodontal disease exacerbates diabetes, they should encourage all diabetic patients to have regular dentist visits. 
Table 2. Adjusted Linear Regression Analysis Predicting Knowledge and Understanding of the Bidirectional Relationship between Diabetes and Periodontal Disease $(n=867)$

\begin{tabular}{|c|c|c|c|c|}
\hline Variables & $B$ & $\mathrm{SE}_{\mathrm{B}}$ & $P$-Value & $95 \% \mathrm{CI}$ \\
\hline \multicolumn{5}{|l|}{ Gender (reference, Female) } \\
\hline Males & -0.038 & 0.009 & $.0001^{\ddagger}$ & $-0.054,-0.019$ \\
\hline \multicolumn{5}{|l|}{ Education (reference, 12th grade or less) } \\
\hline Above 12th grade & 0.030 & 0.010 & $.002^{\dagger}$ & $0.011,0.049$ \\
\hline \multicolumn{5}{|l|}{ Income (reference, low) } \\
\hline Middle & -0.010 & 0.011 & .38 & $-0.031,0.012$ \\
\hline High & 0.026 & 0.014 & .07 & $-0.002,0.055$ \\
\hline \multicolumn{5}{|l|}{ Diabetes treatment (reference, No) } \\
\hline Yes & 0.109 & 0.040 & $.006^{*}$ & $0.031,0.186$ \\
\hline \multicolumn{5}{|c|}{ HCP recommend dentist visit (reference, $N_{0}$ ) } \\
\hline Yes & 0.036 & 0.009 & $.0001^{\ddagger}$ & $0.018,0.054$ \\
\hline \multicolumn{5}{|l|}{ Employment (reference, Employed) } \\
\hline Other & -0.002 & 0.010 & .82 & $-0.022,0.017$ \\
\hline \multicolumn{5}{|l|}{ Health literacy (reference, Adequate) } \\
\hline Marginal/inadequate & -0.056 & 0.011 & $.0001^{\ddagger}$ & $-0.077,-0.034$ \\
\hline \multicolumn{5}{|l|}{ Diabetes type (reference, type 2 diabetes) } \\
\hline Type 1 diabetes & 0.028 & 0.015 & .06 & $-0.001,0.057$ \\
\hline \multicolumn{5}{|l|}{ Marital status (reference, Married) } \\
\hline Not married & -0.002 & 0.011 & .83 & $-0.024,0.019$ \\
\hline Previously married & -0.002 & 0.011 & .84 & $-0.024,0.019$ \\
\hline \multicolumn{5}{|c|}{ Race/ethnicity (reference, non-Hispanic White) } \\
\hline Black or African American & 0.046 & 0.073 & .53 & $-0.097,0.188$ \\
\hline Hispanic/Latino/Spanish origin & 0.071 & 0.073 & .33 & $-0.071,0.214$ \\
\hline Asian & 0.081 & 0.078 & .30 & $-0.072,0.234$ \\
\hline Pacific Islander & 0.081 & 0.077 & .29 & $-0.070,0.231$ \\
\hline Other & 0.053 & 0.082 & .52 & $-0.108,0.214$ \\
\hline \multicolumn{5}{|c|}{ Diabetes education session (reference, Yes) } \\
\hline No & 0.057 & 0.089 & .32 & $-0.118,0.233$ \\
\hline Diabetes duration & 0.004 & 0.003 & .16 & $-0.002,0.010$ \\
\hline \multicolumn{5}{|l|}{ Dental insurance (reference, Yes) } \\
\hline No & -0.013 & 0.009 & .16 & $-0.031,0.005$ \\
\hline \multicolumn{5}{|l|}{ Smoking status (reference, Yes) } \\
\hline No & -0.015 & 0.010 & .16 & $-0.035,0.006$ \\
\hline \multicolumn{5}{|c|}{ Family history of diabetes (reference, Yes) } \\
\hline No & -0.009 & 0.010 & .39 & $-0.029,0.011$ \\
\hline
\end{tabular}

$\mathrm{B}$, unstandardized regression coefficient; $\mathrm{HCP}$, health care provider; $\mathrm{SE}_{\mathrm{B}}$, Standard error of the coefficient. ${ }^{*} P<.05 ;{ }^{\dagger} P<.005 ;{ }^{\ddagger} P<.0001$.

As noted, periodontal disease is the sixth complication of diabetes. Thus, as eye exams, podiatrist visits, and nutritionist consultations are incorporated into diabetes management programs, dental visits should also be incorporated. ${ }^{9,10}$ During initial and follow-up medical appointments for patients with diabetes, health care providers should refer such patients to a dentist and encourage them to keep regular dental appointments.

We believe this is the first study to assess the characteristics regarding knowledge and understanding of the diabetes and periodontal disease bidirectional relationship among patients with diabetes. Nonetheless, our study has limitations. This study was crosssectional. Thus, no causal inferences can be made from the results. We could not confirm participant's diabetes diagnosis, whether their diabetes was controlled, their dental hygiene status, or dental care history. Identifying ways of confirming diabetes diagnosis and control, and dental care history (routine and acute care dental visits, cleanings) should be addressed by future research. Since the survey was 
online, patients with diabetes without access to a computer, the internet, or a smart phone were excluded. Hence, we recommend a comprehensive survey approach-that is, surveys administered in doctors' and dentists' offices, clinics, and community centers.

This study highlights the importance of informing patients with diabetes about their increased risk for developing periodontal disease. Moreover, there is a need for health care providers to recommend that their diabetic patients regularly see a dentist and for dental health providers to remind their diabetic patients to brush and floss regularly to prevent periodontal disease and improve glycemic control. Both provider types should include one another on their respective care and treatment teams. This can be an important first step in eliminating dental- and diabetes-related disparities that leads to patients with diabetes achieving better quality of life.

To see this article online, please go to: http://jabfm.org/content/ 33/6/1004.full.

\section{References}

1. Heron MD. Leading causes for 2017. National vital statistics reports. Hyattsville, MD: National Center for Health Statistics; 2019.

2. American Diabetes Association. Economic costs of diabetes in the US in 2017. Diabetes Care 2018;41:91728.

3. Centers for Disease Control and Prevention. National Diabetes Statistics Report. Centers for Disease Control and Prevention (CDC). 2018. Available from: https://www.cdc.gov/diabetes/data/ statistics/statistics-report.html. Accessed February 16, 2019.

4. Centers for Disease Control and Prevention. Diabetes report card 2017. Updated 2018. Available from: https://www.cdc.gov/diabetes/pdfs/library/diabetesr eportcard2017-508.pdf. Accessed January 15, 2019.

5. Merz CNB, Buse JB, Tuncer D, Twillman GB. Physician attitudes and practices and patient awareness of the cardiovascular complications of diabetes. J Am Coll Cardiol 2002;40:1877-81.

6. Parving H, Lewis J, Ravid M, Remuzzi G, Hunsicker L. Prevalence and risk factors for microalbuminuria in a referred cohort of type II diabetic patients: a global perspective. Kidney Int 2006;69: 2057-63.

7. Shepherd J, Barter P, Carmena R, et al. Effect of lowering LDL cholesterol substantially below currently recommended levels in patients with coronary heart disease and diabetes: the Treating to New Targets (TNT) study. Diabetes Care 2006;29: 1220-6.
8. Thapa R, Poudyal G, Maharjan N, Bernstein PS. Demographics and awareness of diabetic retinopathy among diabetic patients attending the vitreoretinal service at a tertiary eye care center in Nepal. Nepal J Ophthalmol 2012;4:10-6.

9. Taylor GW. Bidirectional interrelationships between diabetes and periodontal diseases: an epidemiologic perspective. Ann Periodontol 2001;6:99-112.

10. Saini R, Saini S, Sugandha R. Periodontal disease: the sixth complication of diabetes. J Fam Commun Med 2011;18:31.

11. Preshaw PM, Alba AL, Herrera D, et al. Periodontitis and diabetes: a two-way relationship. Diabetologia 2012;55:21-31.

12. Morita I, Inagaki K, Nakamura F, et al. Relationship between periodontal status and levels of glycated hemoglobin. J Dent Res 2012;91:161-6.

13. Mirza B, Syed A, Izhar F, Ali Khan A. Bidirectional relationship between diabetes and periodontal disease: review of evidence. J Pakistan Med Assoc 2010;60:766-8.

14. Casanova L, Hughes F, Preshaw P. Diabetes and periodontal disease: a two-way relationship. $\mathrm{Br}$ Dent J 2014;217:433-7.

15. Lalla E, Papapanou PN. Diabetes mellitus and periodontitis: a tale of two common interrelated diseases. Nat Rev Endocrinol 2011;7:738-48.

16. Gümüs P, Buduneli N. Diabetes mellitus and periodontitis: signs of a bidirectional relationship. Eur Med J 2013;1:30-6.

17. Albert DA, Ward A, Allweiss P, et al. Diabetes and oral disease: implications for health professionals. Ann N Y Acad Sci 2012;1255:1-15.

18. Tsai C, Hayes C, Taylor GW. Glycemic control of type 2 diabetes and severe periodontal disease in the US adult population. Community Dent Oral Epidemiol 2002;30:182-92.

19. Saremi A, Nelson RG, Tulloch-Reid M, et al. Periodontal disease and mortality in type 2 diabetes. Diabetes Care 2005;28:27-32.

20. Negrato CA, Tarzia O, Jovanovi冈 L, Chinellato LEM. Periodontal disease and diabetes mellitus. J Appl Oral Sci 2013;21:1-12.

21. Kanjirath PP, Kim SE, Inglehart MR. Diabetes and oral health: the importance of oral health-related behavior. J Dent Hyg 2011;85:264-72.

22. Sanz M, Ceriello A, Buysschaert M, et al. Scientific evidence on the links between periodontal diseases and diabetes: consensus report and guidelines of the joint workshop on periodontal diseases and diabetes by the International Diabetes Federation and the European Federation of Periodontology. J Clin Periodontol 2018;45:138-49.

23. Kim EK, Lee SG, Choi YH, et al. Association between diabetes-related factors and clinical periodontal parameters in type-2 diabetes mellitus. BMC Oral Health 2013;13:64. 
24. Borgnakke WS, Ylöstalo PV, Taylor GW, Genco RJ. Effect of periodontal disease on diabetes: systematic review of epidemiologic observational evidence. J Clin Periodontol 2013;40:S135-S152.

25. Stanko P, Izakovicova Holla L. Bidirectional association between diabetes mellitus and inflammatory periodontal disease. A review. Biomed Pap Med Fac Univ Palacky Olomouc Czech Repub 2014; 158:35-8.

26. Bascones-Martinez A, Gonzalez-Febles J, SanzEsporrin J. Diabetes and periodontal disease. Review of the literature. Am J Dent 2014;27:63-7.

27. Corbella S, Francetti L, Taschieri S, De Siena F, Fabbro MD. Effect of periodontal treatment on glycemic control of patients with diabetes: A systematic review and meta-analysis. J Diabetes Invest 2013;4:502-9.

28. Sun W, Chen L, Zhang S, Wu Y, Ren Y, Qin G. Inflammatory cytokines, adiponectin, insulin resistance and metabolic control after periodontal intervention in patients with type 2 diabetes and chronic periodontitis. Intern Med 2011;50:1569-74.

29. Teeuw WJ, Gerdes VE, Loos BG. Effect of periodontal treatment on glycemic control of diabetic patients: a systematic review and meta-analysis. Diabetes Care 2010;33:421-7.

30. Teshome A, Yitayeh A. The effect of periodontal therapy on glycemic control and fasting plasma glucose level in type 2 diabetic patients: systematic review and meta-analysis. BMC Oral Health 2016;17:31.

31. Darré L, Vergnes JN, Gourdy P, Sixou M. Efficacy of periodontal treatment on glycaemic control in diabetic patients: a meta-analysis of interventional studies. Diabetes Metab 2008;34:497-506.

32. Dommeyer CJ, Baum P, Hanna RW, Chapman KS. Gathering faculty teaching evaluations by in-class and online surveys: their effects on response rates and evaluations. Assess Eval Higher Educ 2004;29:611-23.

33. Watt S, Simpson C, McKillop C, Nunn V. Electronic course surveys: does automating feedback and reporting give better results? Assess Eval Higher Educ 2002;27:325-37.

34. Smith RM, Fleming LE, Arheart KL, Wilkinson JD. Periodontal disease and diabetes: knowledge and attitudes assessment project. Florida Public Health Review 2007;4:12-7.

35. Centers for Disease Control and Prevention. Behavioral Risk Factor Surveillance System Survey Questionnaire. U.S. Department of Health and Human Services, Centers for Disease Control and Prevention. 2018. Available from: https://www.cdc. gov/brfss/questionnaires/index.htm. Accessed April 4, 2019.

36. Kumar S. Oral hygiene awareness among two nonprofessional college students in Chennai, India-A pilot study. Oral Hygiene 2012;5:31-36.

37. Llodra JC, Phantumvanit P, Bourgeois DM, Horn V. LLL 2: an international global level questionnaire on toothbrushing and use of fluoride toothpaste. Int Dent J 2014;64:20-6.

38. Hujoel P, Cunha-Cruz J, Kressin N. Spurious associations in oral epidemiological research: the case of dental flossing and obesity. J Clin Periodontol 2006;33:520-3.

39. American Dental Association Division of Communications. Preventing periodontal disease. J Am Dent Assoc 2001;132:1339.

40. Yuen HK, Wolf BJ, Bandyopadhyay D, Magruder KM, Salinas CF, London SD. Oral health knowledge and behavior among adults with diabetes. Diabetes Res Clin Pract 2009;86:239-46. 